\title{
Methylmalonic acidemia due to methylmalonyl-CoA epimerase deficiency
}

INSERM

\section{Source}

INSERM. (1999). Orphanet: an online rare disease and orphan drug data base.

Methylmalonic acidemia due to methylmalonyl-CoA epimerase deficiency.

ORPHA:308425

Methylmalonic acidemia due to methylmalonyl-CoA epimerase deficiency is a rare inborn error of metabolism disease characterized by mild to moderate, persistent elevation of methylmalonic acid in plasma, urine and cerebrospinal fluid. Clinical presentation may include acute metabolic decompensation with metabolic acidosis (presenting with vomiting, dehydration, confusion, hallucinations), nonspecific neurological symptoms, or may also be asymptomatic. 